\title{
Implementasi Gerakan Ibu Sehat Reproduksi (GERBUSEPRO) dalam Rangka Meningkatkan Status Kesehatan Ibu di Tambakasri Kabupaten Malang
}

\author{
Juwitasari $^{1}$, Dyna Amalia Virganita ${ }^{2}$ \\ ${ }^{1,2}$ Prodi Ilmu Keperawatan Fakultas Ilmu Kesehatan Universitas Muhammadiyah Malang \\ Email korespondensi : juwita@umm.ac.id
}

\begin{abstract}
Abstrak
Perbedaan latar belakang pendidikan, sosial ekonomi, lingkungan dan budaya membuat tingkat pengetahuan ibu tentang pemeliharaan kesehatan reproduksi yang baik dan benar masih sangat rendah. Rendahnya pengetahuan dapat menimbulkan berbagai penyakit dan komplikasi yang serius pada organ reproduksi. Praktisi keperawatan kesehatan seksual dan reproduksi harus membangun jejaring di komunitas dan lingkungan dimana ibu itu tinggal. Tujuan program pengabdian masyarakat kelompok dengan tema implementasi Gerakan Ibu Sehat Reproduksi (GERBUSEPRO) adalah dalam Rangka meningkatkan status kesehatan ibu di Tambakasri Kabupaten Malang. Secara rinci Tujuan tersebut adalah: (a) Untuk meningkatkan pengetahuan ibu tentang kesehatan reproduksi dan (b) Untuk meningkatkan kemampuan ibu dalam merawat kesehatan reproduksi. Metode pengabdian pada masyarakat ini dilakukan melalui pemberian materi klasikal tentang kesehatan reproduksi wanita, yang disampaikan melalui modul dan video pembelajaran, dan demonstrasi tentang perawatan organ reproduksi. Evaluasi awal dan akhir dilakukan dengan melakukan pretest dan postest kepada 20 kader kesehatan dan 30 orang ibu usia reproduksi di wilayah desa Tambakasri, kecamatan Tajinan. Kabupaten Malang. Hasil kegiatan tersebut menunjukkan terjadi peningkatan kemampuan kognitif dan psikomotor ibu di wilayah desa Tambakasri Kabupaten Malang tentang kesehatan reproduksi dari 25\% menjadi 84\%.Pelaksanaan pengabdian Gerakan Ibu Sehat Reproduksi ini sangat efektif dalam meningkatkan kognitif dan psikomotor ibu usia reproduksi di wilayah Tambakasri.
\end{abstract}

Kata kunci : Ibu, Reproduksi, Sehat

\begin{abstract}
Differences in educational, socio-economic, environmental and cultural backgrounds mean that the level of maternal knowledge about good and correct health care is still very low. Lack of knowledge can lead to various serious diseases and complications in the press organs. Sexual and health nursing practitioners should build networks in the community and environment in where the mother lives. The objectives of the group community service program with the theme implementation of the healthy and reproductive mother movement in order to improve maternal health status in Tambakasri, Malang Regency. The obiectives in detail are: (a) To increase maternal knowledge about health and (b) To increase the ability of mothers to care for press health. This method of community service is carried out by presenting classical material on women's health, delivered through learning modules and videos, and about organ care. The initial and final evaluations were carried out by conducting a pretest and posttest on 20 health cadres and 30 aged mothers in the Tambakasri village area, Tajinan sub-district. Malang Regency. The results of these activities indicate an increase in cognitive and psychomotor abilities of mothers in the Tambakasri village of Malang Regency regarding health from $25 \%$ to $84 \%$. The implementation of the reproductive healthy mother movement service is very effective in improving the cognitive and psychomotor age of mothers in the Tambakasri area.
\end{abstract}

Keywords: health, mother, reproduction 


\section{PENDAHULUAN}

Kualitas kesehatan reproduksi seorang ibu mulai dari calon pengantin sampai wanita yang aktif secara reproduksi saat ini sangat mempengaruhi kualitas Sumber Daya Penduduk Indonesia di masa depan (Dila, 2019). Seorang ibu sekarang harus dalam kondisi sehat dan kuat agar ke depannya mampu melahirkan generasi yang berkualitas. Oleh karena itu, perawat perlu melakukan tindakan promotif dan preventif untuk meningkatkan kualitas kesehatan reproduksi seorang ibu demi peningkatan kualitas Sumber Daya Manusia Indonesia ke depan. Kesehatan reproduksi adalah suatu kondisi fisik, mental, dan sosial yang utuh, bukan hanya terbebas dari penyakit atau kecacatan yang berkaitan dengan sistem, fungsi, dan proses reproduksi. Di dunia ini, populasi ibu berusia dibawah 24 tahun mencapai setengah dari keseluruhan populasi (1.8 milyar) dan sembilan puluh persen nya tinggal di negara berkembang (Sutanto, dkk, 2019). Banyak ibu yang tinggal di negara berkembang hidup dalam kemiskinan dan tidak bekerja.

Upaya peningkatan kesehatan reproduksi ibu diharapkan berdampak signifikan pada kehidupan reproduksi ibu (Emilia, O., \& Prabandari, 2019). Peran perawat sangat penting dalam menjadi pelindung dengan memberikan dukungan, tidak menghakimi dan pelayanan yang tepat untuk ibu. Praktisi keperawatan kesehatan seksual dan reproduksi harus membangun jejaring di komunitas dan lingkungan dimana ibu itu tinggal (Rakinaung, dkk., 2019). Pendekatan mendalam oleh praktisi keperawatan dalam bentuk gerakan seorang ibu sehat reproduksi (GERBUSEPRO), Gerakan seorang ibu sehat reproduksi (GERBUSEPRO) memfasilitasi aktualisasi determinan sosial kesehatan reproduksi ibu yang mencakup 4 ruang lingkup: menciptakan lingkungan sadar sehat reproduksi, pendidikan reproduksi yang memadai, perawatan kesehatan reproduksi ibu dan evaluasi gerakan seorang ibu sehat reproduksi (Nugraha, dkk., 2014).

Peningkatan kualitas kesehatan reproduksi ibu merupakan tugas besar yang harus melibatkan semua lapisan dan kader Kesehatan setempat, khususnya di wilayah desa Tambak Asri Kecamatan Tajinan Kabupaten Malang. Revitalisasi peran kader Kesehatan merupakan pengkaderan seorang ibu yang saat ini berjumlah sekitar 20 orang dan ibu usia reproduksi yang tidak kurang dari 100 orang. Kader Kesehatan inilah yang akan menjadi ujung tombak dan penggerak kelompok ibu-ibu untuk meningkatkan kesehatan reproduksinya. Kader kesehatan yang dipilih adalah ibu-ibu di wilayah Tambakasri, dan bekerja secara sukarela untuk menjadi penyelenggara kegiatan pemberdayaan masyarakat di bidang Kesehatan, yang 
dalam hal ini adalah Kesehatan reproduksi (Tjahyowati,dkk 1997).

Tujuan program pengabdian masyarakat kelompok dengan tema Implementasi Gerakan Ibu Sehat Reproduksi (GERBUSEPRO) adalah dalam rangka meningkatkan status kesehatan ibu di Tambakasri Kabupaten Malang. Secara rinci tujuan tersebut adalah: (a) Untuk meningkatkan pengetahuan ibu tentang kesehatan reproduksi dan (b) Untuk meningkatkan kemampuan ibu dalam merawat kesehatan reproduksi. Kegiatan yang dilakukan meliputi pendekatan kepada mitra dalam hal ini kader dan ibu-ibu usia produktif, membuat modul untuk kader, koordinasi dengan bidan Desa guna peningkatan kesadaran Kesehatan reproduksi (Nain, 2015).

Pengetahuan kesehatan reproduksi yang cukup, dapat menjadi bekal pelengkap seorang ibu untuk selalu sehat, dan meneruskan siklus reproduksinya tanpa rasa khawatir (Elsas, 2019). Disamping pengetahuan fisiologis dasar dan cara merawat organ kewanitaan secara benar yang dahulu mungkin telah didapatkan di bangku Pendidikan Dasar. Sistem reproduksi yang sehat akan menurunkan angka morbiditas dan mortalitas pada ibu usia subur di Indonesia di masa depan.

\section{MASALAH}

Kurangnya pembinaan dan pelatihan oleh tenaga kesehatan tentang pengetahuan dan skill perawatan kesehatan reproduksi pada ibu usia produktif di wilayah Desa Tambakasri kecamatan Tajinan Kabupaten Malang. Hasil studi yang pernah dilakukan di kecamatan Tajinan pada tahun 2019, menunjukkan bahwa dukungan suami dalam menjaga Kesehatan reproduksi istri dalam kategori rendah (Windari et al., 2019). Oleh karena itu, setelah dilakukan gerakan ibu sehat reproduksi diharapkan dapat menurunkan penyakit system reproduksi dan komplikasinya, sehingga terwujud seorang ibu dan masyarakat yang sehat reproduksi.

\section{METODE}

1) Model Pengabdian Kepada Masyarakat

Model yang digunakan dalam kegiatan pengabdian ini adalah dengan menggunakan model peningkatan kemitraan dengan kader Kesehatan dan ibu-ibu PKK di Desa Tambak Asri Tajinan Kabupaten Malang, untuk memberikan dasar kesehatan dan pemeliharaan organ 
reproduksi ibu-ibu. Pendekatan yang dilakukan adalah dengan memberikan pembinaan secara langsung pada kader kesehatan dan ibu-ibu PKK.

Metode pengabdian tersebut sebagai berikut:

a. Identifikasi awal masalah yang ditemukan berupa kurangnya tingkat pengetahuan dan skill tentang Kesehatan dan pemeliharaan organ reproduksi pada ibu-ibu PKK dan kader kesehatan di Desa Tambak Asri Tajinan Kabupaten Malang.

b. Memberikan materi kesehatan reproduksi dan skill perawatan Kesehatan reproduksi pada para kader dan ibu-ibu usia produktif di Desa Tambak Asri Tajinan Kabupaten Malang (women empowerment) dan motivasi agar mereka sadar untuk sehat reproduksi.

c. Pembuatan produk pengabdian berupa modul kesehatan reproduksi dan kompilasi video personal hygiene dan siklus menstruasi.

d. Penguatan materi, konsep dan skill tentang kesehatan reproduksi.

Pengabdian Masyarakat yang dilakukan di wilayah Desa Tambakasri Kecamatan Tajinan Kabupaten Malang Jawa Timur ini dimulai dengan melakukan analisis situasi, analisis masalah dan membentuk kemitraan dengan kader Kesehatan dan ibu PKK. Peningkatan kemitraan dengan masyarakat dalam pengabdian GERBUSEPRO dicapai dengan persetujuan Ibu Kepala Desa Setempat, ketua PKK dan segenap kader Kesehatan. Pelaksanaan pengabdian masyarakat ini menggunakan konsep Woman Empowerment, dengan meningkatkan kemampuan wanita usia reproduktif tersebut untuk mensejahterakan diri sendiri dalam kesehatan reproduksi.

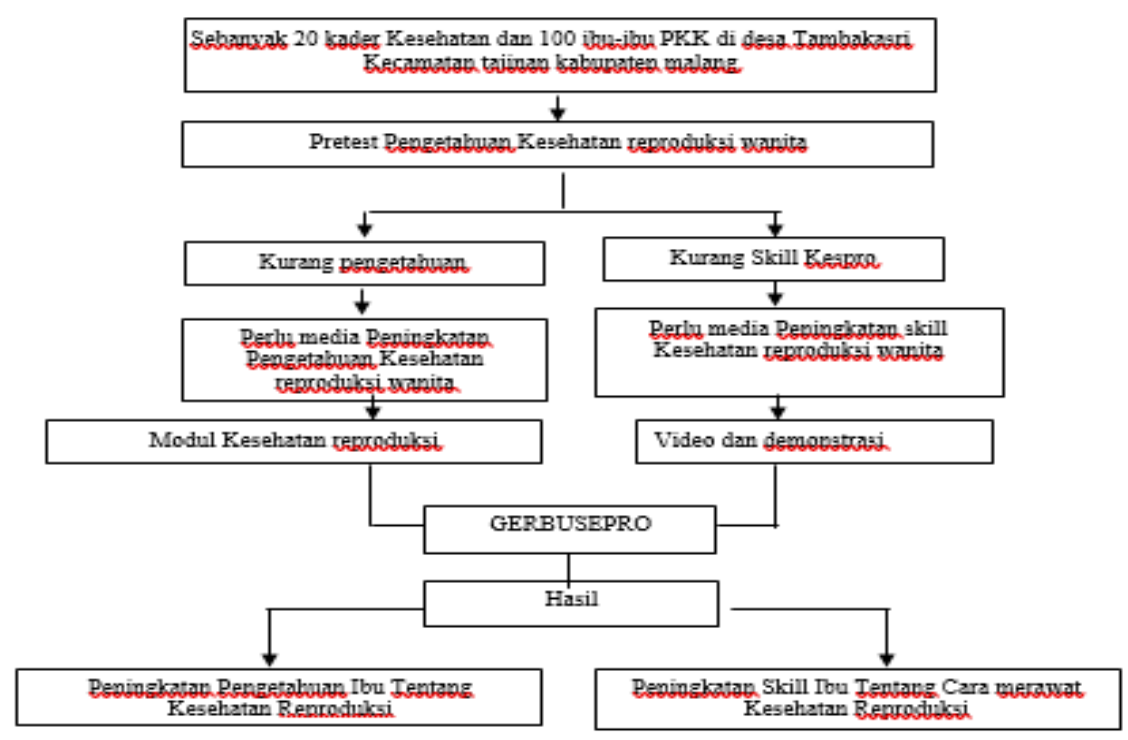

Gambar 1. Gambaran Pelaksanakan Kegiatan Pengabdian 
2) Tempat Kegiatan Pengabdian Kepada Masyarakat

Pelaksanaan kegiatan pengabdian kepada masyarakat ini pertemuannya dilaksanakan di balai pertemuan Masjid Jami Tambakasri, Tajinan, Kabupaten Malang.

3) Jadwal Kegiatan Pengabdian Kepada Masyarakat

Tabel 1. Jadwal Kegiatan Pengabdian Kepada Masyarakat

\begin{tabular}{|c|c|c|c|}
\hline $\begin{array}{c}\text { Fokus } \\
\text { Pengabdian }\end{array}$ & $\begin{array}{c}\text { Bentuk } \\
\text { Kegiatan }\end{array}$ & Indikator Keberhasilan & $\begin{array}{c}\text { Waktu } \\
\text { Pelaksanaan } \\
\text { Kegiatan }\end{array}$ \\
\hline $\begin{array}{l}\text { Menguatkan } \\
\text { konsep } \\
\text { Kesehatan } \\
\text { reproduksi }\end{array}$ & $\begin{array}{l}\text { 1. Brainstorming konsep } \\
\text { kesehatan reproduksi } \\
\text { 2. Pretest } \\
\text { 3. Video demonstrasi } \\
\text { tentang mengenali organ } \\
\text { reproduksi wanita }\end{array}$ & $\begin{array}{l}\text { Mengidentifikasi } \\
\text { pengetahuan awal } \\
\text { Anatomi kesehatan } \\
\text { reproduksi seorang ibu }\end{array}$ & $\begin{array}{l}10 \text { November } \\
2019\end{array}$ \\
\hline $\begin{array}{l}\text { Pembuatan } \\
\text { produk } \\
\text { pengabdian }\end{array}$ & 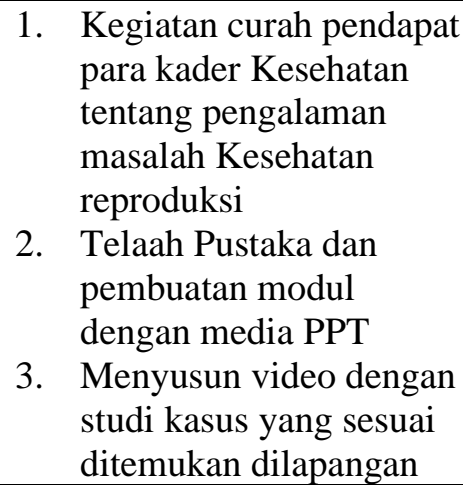 & $\begin{array}{l}\text { Terbentuknya modul } \\
\text { dan video } \\
\text { pembelajaran } \\
\text { Kesehatan reproduksi } \\
\text { untuk kader Kesehatan } \\
\text { dan ibu-ibu PKK }\end{array}$ & 11 Juni 2020 \\
\hline $\begin{array}{l}\text { Pendalaman } \\
\text { serta } \\
\text { melatih } \\
\text { keterampilan/ } \\
\text { skill personal } \\
\text { hygiene. }\end{array}$ & 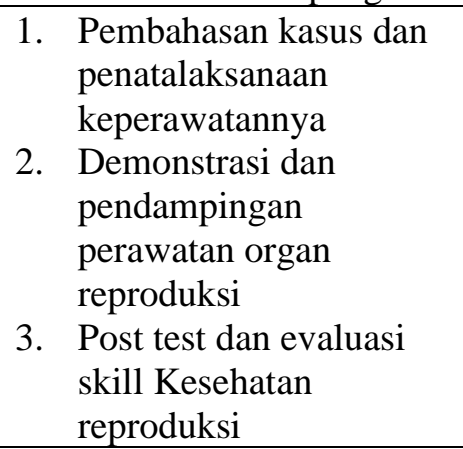 & $\begin{array}{l}\text { Pelaksanaan kegiatan } \\
\text { lancar dan ketercapaian } \\
\text { materi }\end{array}$ & $\begin{array}{l}28 \text { Agustus } \\
2020\end{array}$ \\
\hline
\end{tabular}

\section{HASIL DAN PEMBAHASAN}

\section{1) Hasil}

Setelah dilakukan pemberian materi pengabdian Masyarakat dilanjutkan dengan sesi Curah pengalaman dan pendapat mengenai konsep yang telah di dapat. Hasil dari pemberian materi tersebut didapatkan data bahwa 5 orang ibu dari total 100 peserta mengatakan pernah mengalami masalah pada organ reproduksinya berupa keputihan yang menahun,, dan rasa 
gatal dan tidak nyaman karena pemilihan produk yang salah dalam merawat organ kewanitaannya.

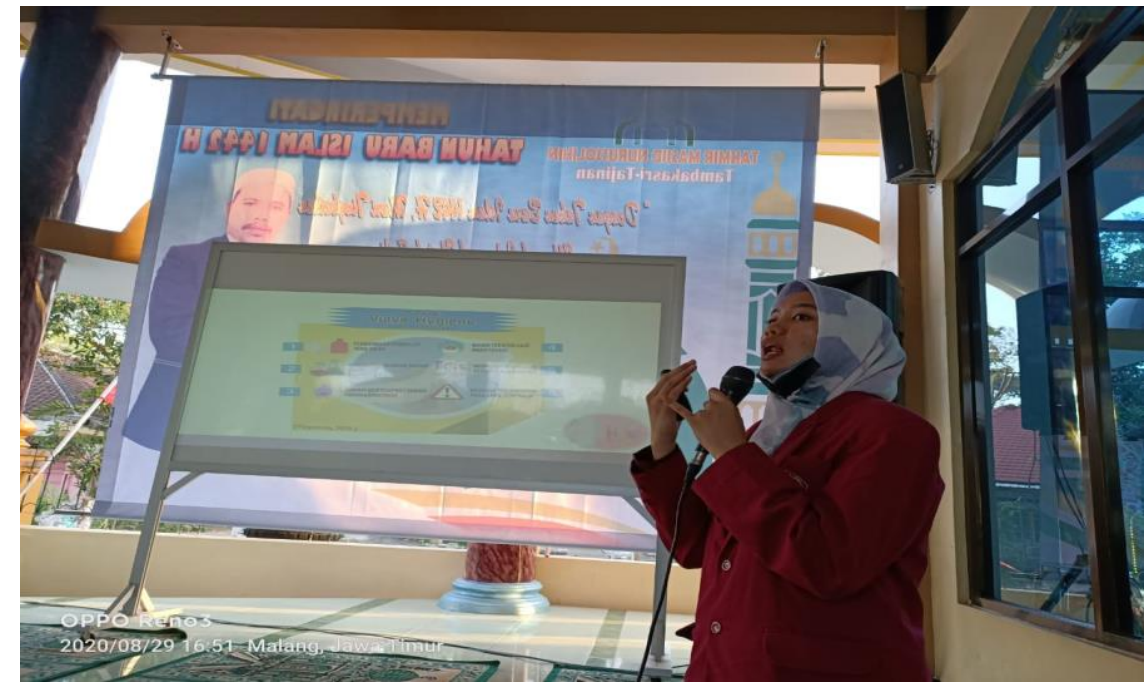

Gambar 2. Pembukaan Sesi Materi Pengabdian Masyarakat GERBUSEPRO

Kegiatan pengabdian masyarakat yang dilaksanakan di Desa Tambakasri Kecamatan Tajinan Kabupaten Malang, Jalan Haji Sholeh no 32 Kode Pos 65172. Pengabdian ini diikuti kurang lebih 20 kader Kesehatan aktif dan 100 wanita usia reproduktif di desa Tambakasri.

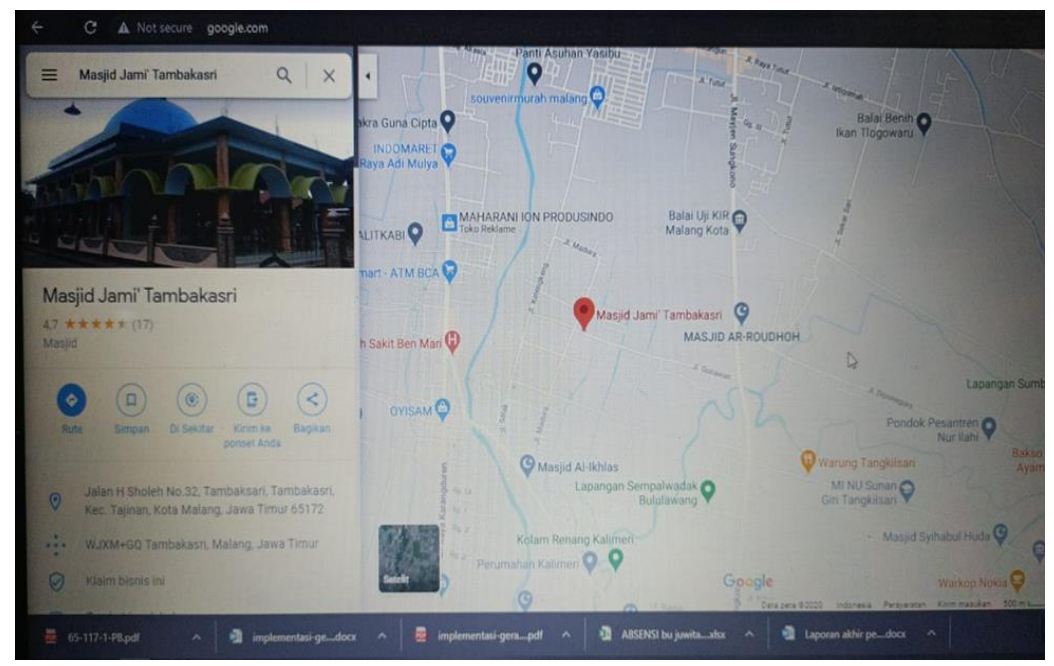

Gambar 3. Lokasi Pengabdian Masyarakat GERBUSEPRO

Kegiatan yang dilaksanakan dalam pengabdian GERBUSEPRO ini diawali dengan pembuatan produk pembelajaran Kesehatan reproduksi, pendampingan dan pelatihan cara melakukan menjaga kebersihan organ reproduksi yang tepat dan benar, melakukan demonstrasi perawatan organ reproduksi yang benar dan tepat, serta melakukan evaluasi berupa tanya jawab seputar Kesehatan organ reproduksi. 


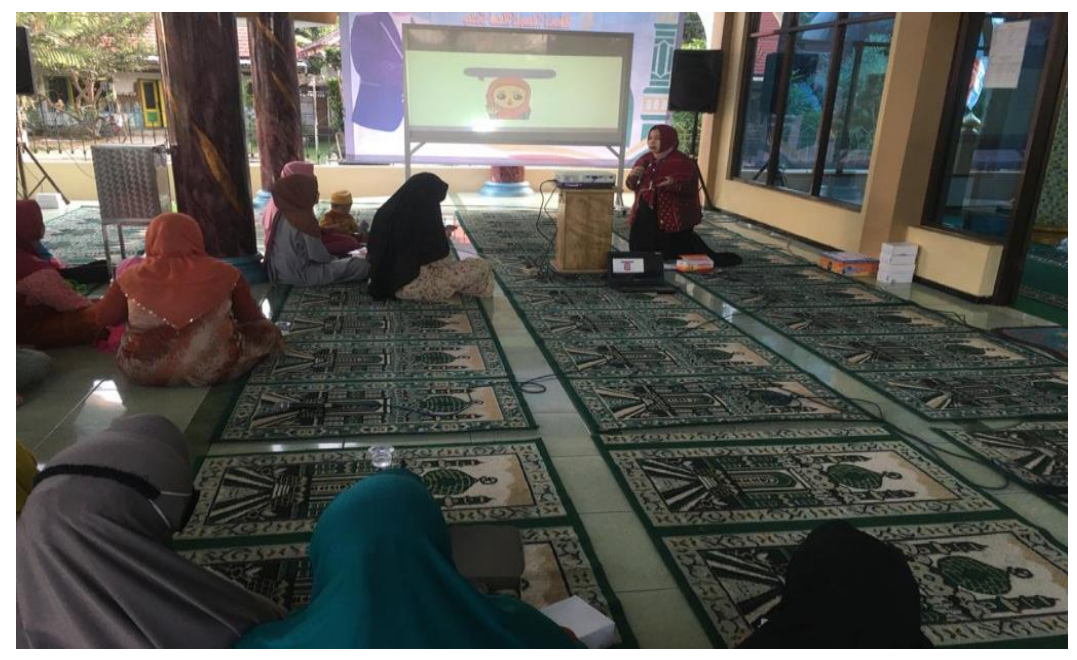

Gambar 4. Materi Perawatan Organ Reproduksi Wanita

Terdapat peningkatan secara signifikan tingkat pengetahuan Kesehatan reproduksi, dan perawatan organ reproduksi Ibu-ibu PKK dan kader Kesehatan di wilayah desa Tambakasri Kabupaten Malang tentang kesehatan reproduksi dari 25\% menjadi 84\% setelah dilaksanakan pengabdian masyarakat.Pengkajian tingkat pengetahuan ibu dilakukan dengan memberikan kuesioner pengetahuan dan sikap tentang Kesehatan reproduksi wanita dan vulva hygiene sebanyak 15 poin pertanyaan pilihan ganda. Nilai rata-rata terendah hasil pretes adalah 27 dan nilai rata-rata yang tertinggi 47. Nilai rata-rata terendah hasil postes adalah 53 dan nilai ratarata yang tertinggi 93 .

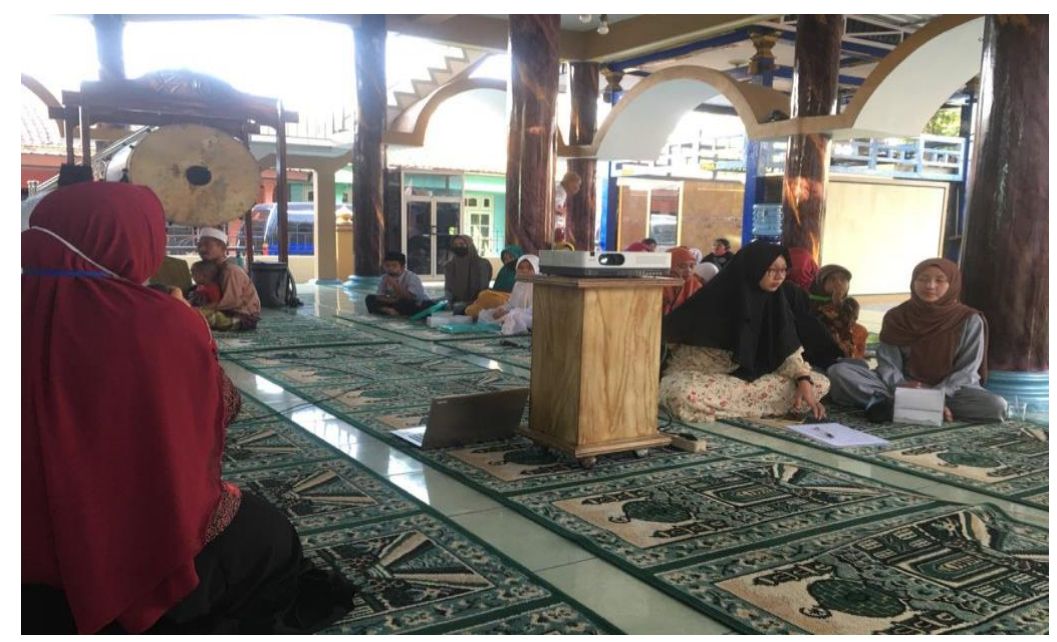

Gambar 5. Evaluasi Materi dan Skill Perawatan Organ Reproduksi Wanita

\section{2) Pembahasan}

Menurut Lilik Hanifa (2017) pengetahuan dipengaruhi oleh beberapa faktor salah satunya usia. Usia menggambarkan kematangan fisik, kematangan psikis dan sosial yang 
dapat mempengaruhi proses belajar remaja. Usia menjadi salah satu faktor yang mempengaruhi penangkapan informasi atau pengetahuan yang pada akhirnya akan mempengaruhi tingkat pengetahuan wanita itu sendiri (Hanifah \& Sri, 2017). Para ibu di desa tambakasri, dan para kader sama sekali belum paham tentang konsep Kesehatan reproduksi mulai dari Kesehatan saat menstruasi awal hingga menjelang menopause. Ibu-ibu dan para kader juga belum paham cara merawat organ reproduksi wanita dengan baik dan benar.

Menurut Rihardini (2019) usia awal menstruasi berhubungan sekali dengan pengetahuan dan pengalaman saat menstruasi dan hal tersebut akan berpengaruh pada perilaku perawatan diri saat menstruasi (Solehati et al., 2017). Pada penelitian ini tingkat pengetahuan wanita cenderung kurang, hal tersebut bisa disebabkan oleh kurangnya pemberian informasi Kesehatan reproduksi, dan kurangnya pemberian pemahaman dari lingkungan sekitar tentang Vulva Hygiene. Hal tersebut yang menyebabkan kurangnya pengetahuan.

Pada analisa data diatas didapatkan hasil bahwa para wanita lebih banyak mendapatkan informasi dari ibu selaku orang tua. Menurut Ristraningsih (2017) menyatakan bahwa orang tua sangat berpengaruh dalam memberikan pemahaman kepada seorang anak, salah satunya memberikan pengetahuan kesehatan. Pada dasarnya Pendidikan kesehatan reproduksi yang paling utama adalah dari orang tua itu sendiri tetapi apabila pengetahuan orang tua kurang memadahi atau awam akan menyebabkan kurangnya pemahaman terhadap anak dan orang tua akan cederung tidak memberikan informasi yang seharusnya diberikan kepada anak (Ristraningsih, 2017).

\section{KESIMPULAN}

Masalah utama yang dialami oleh kader dan ibu- ibu di wilayah Desa Tambakasri Keluarahan Tajinan Kabupaten Malang adalah rendahnya pengetahuan dan ketrampilan tentang bagaimana menjaga kebersihan organ reproduksi yang tepat dan benar. Serta semua kader dan ibu-ibu usia produktif belum pernah memperagakan cara membersihkannya. Setelah dilakukan kegiatan pengabdian berupa pendampingan dan pelatihan, ibu-ibu dan kader mampu melakukan perawatan organ reproduksi yang tepat dan benar, saat menstruasi dan saat tidak menstruasi . Dengan demikian tujuan kegiatan ini yaitu memberdayakan masyarakat khususnya kader dan ibu- ibu di wilayah Desa Tambakasri Keluarahan Tajinan Kabupaten Malang dapat ditingkatkan. Harapannya dapat mencegah secara dini penyakit-penyakit organ reproduksi yang muncul sebelum korban dibawa ke Rumah Sakit. 
Saran berikutnya diperlukan adanya kegiatan berkesinambungan berbasis kemitraan antara praktisi Kesehatan, dengan masyarakat sebagai langkah monitoring dan follow up pada para kader Kesehatan dan ibu-ibu PKK dalam rangka meningkatkan kesejahteraan Kesehatan reproduksi wanita usia reproduktif. Pembinaan dan skrining secara berkala dengan mitra pengabdian ini sangat penting dilakukan walaupun kegiatan sudah berakhir sebagai Langkah promosi kesehatan.

\section{DAFTAR PUSTAKA}

Dila, D. S. (2019). Pengaruh Penyuluhan Kesehatan Reproduksi Terhadap Pengetahuan Catin Wanita dalam Persiapan Pra Nikah di Wilayah Kerja KUA Kecamatan Koto Tangah pada Tahun 2019. Universitas Andalas.

Elsas, S. W. (2019). PERNIKAHAN DINI (Studi Antropologi di Jorong Mawar II, Nagari Lubuk Jantan, Kecamatan Lintau Buo Utara, Kabupaten Tanah Datar, Provinsi Sumatera Barat). Universitas Andalas.

Emilia, O., \& Prabandari, Y. S. (2019). Promosi kesehatan dalam lingkup kesehatan reproduksi. UGM PRESS.

Hanifah, L., \& Sri, S. (2017). Hubungan usia dengan pengetahuan remaja putri tentang pemeriksaan payudara sendiri ( SADARI ). STIKES Mamba'ul 'Ulum Surakarta, 39-47.

Karakteristik, H., Usia, I. B. U., Dan, P., Sosial, D., Dengan, S., Senam, K., \& Pandanmulyo, D. I. D. (2019). Hubungan karakteristik ibu (usia, paritas, pendidikan) dan dukungan sosial suami dengan keikutsertaan senam hamil di desa pandanmulyo. November 2018, 30-40.

Ristraningsih, G. P. (2017). Remaja Pada Siswi Kelas Viii Di Smp Negeri 28 Semarang. Pengaruh Pendidikan Kesehatan Terhadap Tingkat Pengetahuan Kesehatan Reproduksi Remaja Pada Siswa VIII Di SMPN 28 Semarang.

Solehati, T., E, E., Trisyani, M., \& Hermayanti, Y. (2017). Hubungan Sumber Informasi dan Usia Remaja Puteri dengan Perilaku Perawatan Diri saat Menstruasi. Jurnal Keperawatan Padjadjaran, 5(2), 145-154. https://doi.org/10.24198/jkp.v5i2.452 